\title{
Cellulase Activity in Blood Cockle (Anadara granosa) in the Matang Mangrove Forest Reserve, Malaysia
}

\author{
Takatoshi NIIYAMA ${ }^{1,3}$, Haruhiko TOYOHARA ${ }^{1 *}$ and Katsuhisa TANAKA ${ }^{2}$ \\ ${ }^{1}$ Division of Applied Biosciences, Graduate School of Agriculture, Kyoto University (Kyoto, Kyoto \\ 606-8502, Japan) \\ ${ }^{2}$ Fisheries Division, Japan International Research Center for Agricultural Sciences (Tsukuba, Ibaraki \\ 305-8686, Japan)
}

\begin{abstract}
To validate the utilization of organic matter, mainly composed of cellulose derived from mangrove trees by bivalves, we analyzed the cellulase activity in blood cockles (Anadara granosa) in the Mantang Mangrove Forest Reserve, Malaysia. In an agar plate assay, unstained circles due to cellulase activity were clearly detected in the extract of blood cockle digestive organs. Additionally, SDS-PAGE zymographic analysis revealed intensive active bands at $9.5 \mathrm{kDa}$ and weak smear bands above 24.5 $\mathrm{kDa}$. These results clearly showed that the blood cockle, the dominant mangrove bivalve species, possesses cellulase activity used to break down cellulose derived from mangrove trees. The present paper first reports the occurrence of the cellulose breakdown function in a mangrove bivalve, blood cockle, via biochemical analyses and suggests the possible ecological function of this species in the mangrove food chain.
\end{abstract}

Discipline: Fisheries

Additional key words: agar plate assay, cellulose, digestive organs, zymography

\section{Introduction}

Mangrove areas exhibit especially high biological production due to their specific ecological properties. This may be attributable to their complicated root structures, which appeal as places for larval fish to hide, and mangrove liter nutritionally utilized for mangrove animals as a carbon source ${ }^{4}$. Proper understanding of the ecological system is important to maintain fishery resources and ensure efficient fisheries in mangrove areas. However, it remains unclear whether mangrove liter is actually assimilated by benthic animals in mangroves. The Matang Mangrove Forest Reserve (MMFR) is one of the largest of its kind in Peninsular Malaysia (40,151 ha), within which mangrove crabs, shrimps and bivalves are captured. The blood cockle (Anadara granosa), which has hemoglobin and effectively adapts to the prevailing low oxygen condition, is a dominant benthic animal in the MMFR estuaries, where it is cultured ${ }^{12}$ and one of the key fishery bivalves ${ }^{12}$. However, it is unknown whether the blood cockle can assimilate mangrove liters.

Cellulose, a major component of mangrove trees, is a glucose polysaccharide with a high molecular weight; bound by $\beta-1,4$ linkage and biochemically stable compared with starch, in which glucose is bound by $\alpha-1,4$ and $\alpha-1,6$ linkages ${ }^{6}$. Cellulose degradation proceeds following two steps ${ }^{26}$. Cellulose is initially hydrolyzed by endo$\beta-1,4$-glucanase and/or cellobiohydrolase to form cellodextrin and cellobiose, which are furthered degraded to glucose by $\beta$-glucosidase. Cellulase is the collective name for the enzymes involved in the above steps. Conversely, herbivores have been assumed to digest cellulose by cellulases derived from symbiotic microorganisms before 1998 when the endogenous cellulase gene of the termite was validated to be encoded on the termite chromosome DNA $^{5}$. Since this time, proof that various cellulase genes are encoded on the chromosomes of herbivores has been establihed ${ }^{9,11,15,21,23}$. These findings suggested that the blood cockle possesses cellulase activity and assimilates mangrove liter as a carbon source. In the present study, we attempted to detect cellulase activity in this species to

\footnotetext{
Present address:

${ }^{3}$ Kyoto City, Kyoto City Environmental Policy Bureau (Nakagyo, Kyoto 604-8571, Japan)

* Corresponding author: e-mail toyohara@kais.kyoto-u.ac.jp

Received 24 November 2011; accepted 2 February 2012.
} 
implicate it in cellulose breakdown systems in mangrove areas.

\section{Materials and methods}

\section{Materials}

Blood cockles were collected in MMFR in Perak, Malaysia in September 2010. Figure 1 shows details of the collection sites. Blood cockles were carried alive to the laboratory in Penang City and kept for two days in the aquatic tank to completely excrete the contents of the digestive tract. They were then dissected on ice, whereupon their digestive glands, including the hepatopancreas, were respectively identified. Three volumes (volume/ weight) of iced phosphate buffered saline (PBS) containing $140 \mathrm{mM} \mathrm{NaCl}, 2.7 \mathrm{mM} \mathrm{KCl}, 8 \mathrm{mM} \mathrm{Na}_{2} \mathrm{HPO}_{4}$ and 1.5 $\mathrm{mM} \mathrm{KH} \mathrm{PO}_{4}(\mathrm{pH} 7.4)$ was added to the dissected organs and homogenized for each blood cockle. The homogenates were then centrifuged at $9,100 \times g$ for $10 \mathrm{~min}$, and the supernatants were used as the enzyme solution. The protein concentration of the enzyme solution was measured using the Bradford method ${ }^{2}$, adjusted at $1 \mathrm{mg} \mathrm{ml}^{-1}$ with PBS and stored at $-30^{\circ} \mathrm{C}$ till the enzyme activity as- say. Bovine serum albumin was used as the standard to determine the protein concentration.

\section{Detection of cellulase activity by agar plate assay}

An agar plate assay was performed according to the method of Sakamoto et al. ${ }^{20}$ with slight modifications. A mixture containing 1.5\% agar (Wako Pure Chemical Industries, Osaka, Japan) and $0.5 \%$ carboxymethylcellulose (CMC) (Sigma, St. Louis, MO, USA) dissolved in 100 $\mathrm{mM}$ sodium acetate buffer $(\mathrm{pH}$ 5.5) was heated and soaked into a plastic plate. After cooling, wells of $4.0 \mathrm{~mm}$ diameter ware punched into the plates. Twenty five micro liters of the enzyme solution $(1 \mathrm{mg} / \mathrm{ml})$ was deposited into the wells, and the plate was incubated at $37^{\circ} \mathrm{C}$ overnight. Subsequently, the plate was stained by Congo Red $(0.1 \%)$ for $3 \mathrm{~h}$, and destained with $1 \mathrm{M} \mathrm{NaCl}$.

\section{Detection of cellulase activity by SDS-PAGE zymographic analysis}

Cellulase zymographic analysis was performed using 7.5 or $10 \%$ SDS-PAGE gel containing $0.5 \%$ CMC. Electrophoresis was performed by using the ATTO AE6500. Following electrophoresis, the gels were soaked in

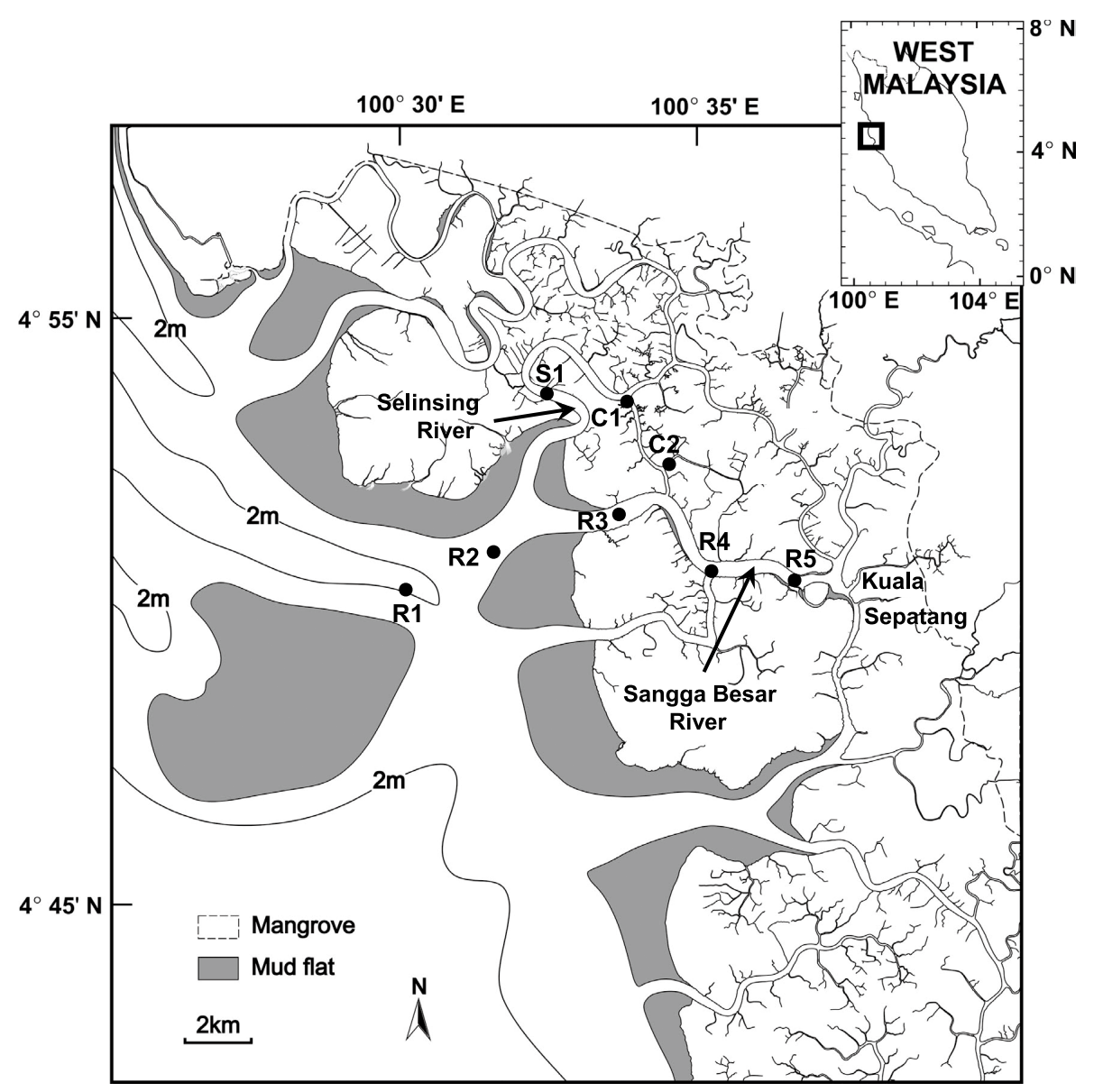

Fig. 1. Collection sites of blood cockles in the Matang Mangrove Forest Reserve in Malaysia 
$10 \mathrm{mM}$ acetate buffer $(\mathrm{pH}$ 5.5) containing $0.1 \%$ TritonX-100 for $30 \mathrm{~min}$ to remove SDS from the gels. The gels were then transferred to $10 \mathrm{mM}$ acetate buffer $(\mathrm{pH}$ 5.5), incubated at $37^{\circ} \mathrm{C}$ overnight, and then stained with $0.1 \%$ Congo Red. The gels were destained using $1 \mathrm{M}$ $\mathrm{NaCl}$. The active bands were detected as non-stained bands.

\section{Evaluation of cellulase activities by measuring the releasing glucose}

Glucose releasing activity from $\mathrm{CMC}$ was evaluated in accordance with the method of Hayano et al..$^{22}$ by using tetrazolium as a coloring agent ${ }^{3}$. Five micro liters of enzyme solution, $5 \mu 1$ of sodium acetate buffer ( $\mathrm{pH} \mathrm{5.5)} \mathrm{and}$ $40 \mu 1$ of $1 \% \mathrm{CMC}$ were added and incubated in a waterbath at $37^{\circ} \mathrm{C}$ for $10 \mathrm{~min}$. The same reaction mixture containing water instead of $\mathrm{CMC}$ solution was taken as a control. After incubation, the tubes were heated at $100{ }^{\circ} \mathrm{C}$ for $3 \mathrm{~min}$ to deactivate the enzyme. One milliliter of tetrazolium was added to the tube and heated at $100^{\circ} \mathrm{C}$ for 4 min in a block incubator (LSE digital dry block, Corning Co. Ltd) and the absorbance at $660 \mathrm{~nm}$ was measured after cooling by a spectrophotometer (Lambda 20, Perkin Elmer Co. Ltd). The value of the absorbance was converted to glucose concentration using a standard glucose curve $\left(0-180 \mu \mathrm{g} \mathrm{ml}^{-1}\right)$, which was made at the same time. The activity was expressed in the form of released $\mu \mathrm{mol}$ glucose min $^{-1}$ mg-protein ${ }^{-1}$.

\section{Results}

\section{Detection of cellulase activity by plate assay and SDS-PAGE zymography}

As shown in Fig. 2, an unstained circle that demonstrated cellulase activity was clearly detected in the extract of blood cockle digestive organs, including the hepatopancreas. SDS-PAGE zymographic analysis revealed intensive active bands at $9.5 \mathrm{kDa}$ and weak smear bands above $24.5 \mathrm{kDa}$ respectively (Fig. 3).

\section{Evaluation of cellulase activities by releasing glucose}

As shown in Fig. 4, the average amounts of glucose formed were $0.16 \mu \mathrm{mol} \mathrm{min}^{-1} \mathrm{mg}$-protein ${ }^{-1}$. In comparison with each activity level, blood cockles collected at R3 showed significantly lower values $\left(0.082 \mu \mathrm{mol} \mathrm{min}^{-1} \mathrm{mg}\right.$ protein $^{-1}$ ) than other sites (sites R5, R4, C1, C2, S1).

\section{Discussion}

The present study was carried out using SDS-PAGE zymographic analysis and assessment of glucose releas- ing activity to validate whether blood cockles possess cellulase activities. Recent stable isotopic analysis showed that a brackish water clam, Corbicula japonica, consumes land-derived organic materials mainly composed of cellulose $\mathrm{e}^{7,8}$. Identification of the intrinsic cellulase gene and immunological detection of the enzyme protein in $C$. japonica strongly suggest that $C$. japonica plays an important role in the process of degradation of cellulose in rivers ${ }^{15-19}$.

Cellulases from bacteria ${ }^{13}$, filamentous fungi ${ }^{24}$, basidiomycete $^{25}$, myxomycete ${ }^{14}$ and protozoan ${ }^{1}$ have been elaborately studied, and the occurrence of cellulase, genes of which are encoded on chromosomes of their

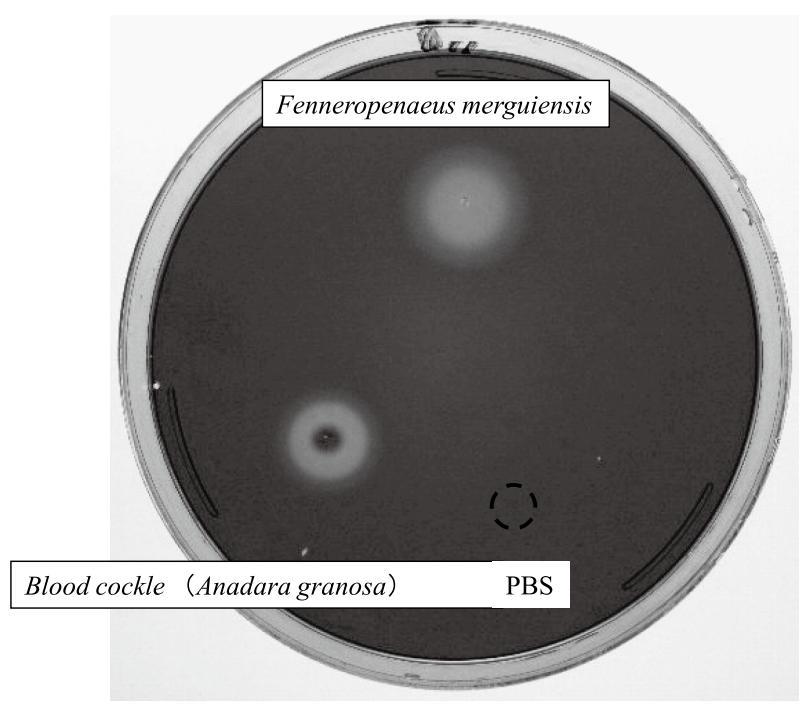

Fig. 2. Agar plate assay of blood cockle digestive organ cellulase

Fenneropenaeus merguiensis cellulase was used as a positive control, while phosphate buffered saline (PBS) was used as a negative control.

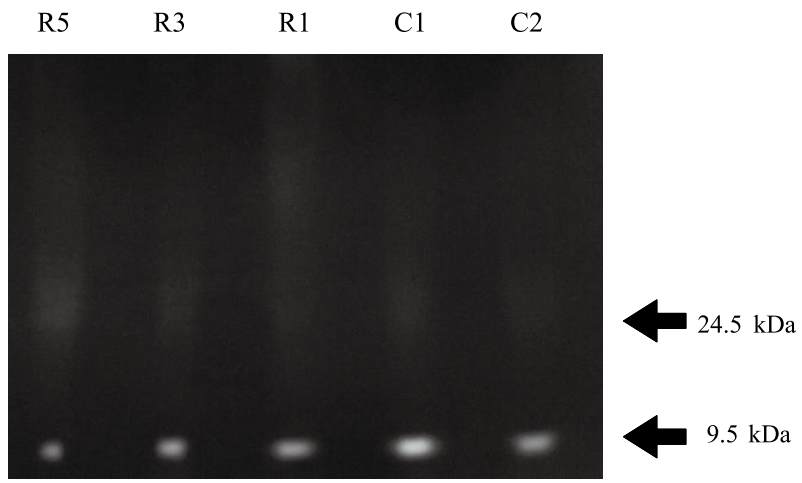

Fig. 3. SDS-PAGE zymographic analysis of digestive organ cellulases of blood cockles collected from different sites

$\mathrm{C} 1, \mathrm{C} 2, \mathrm{R} 1, \mathrm{R} 3$ and R5 show the locations of the collection sites referred to in Fig. 1. 


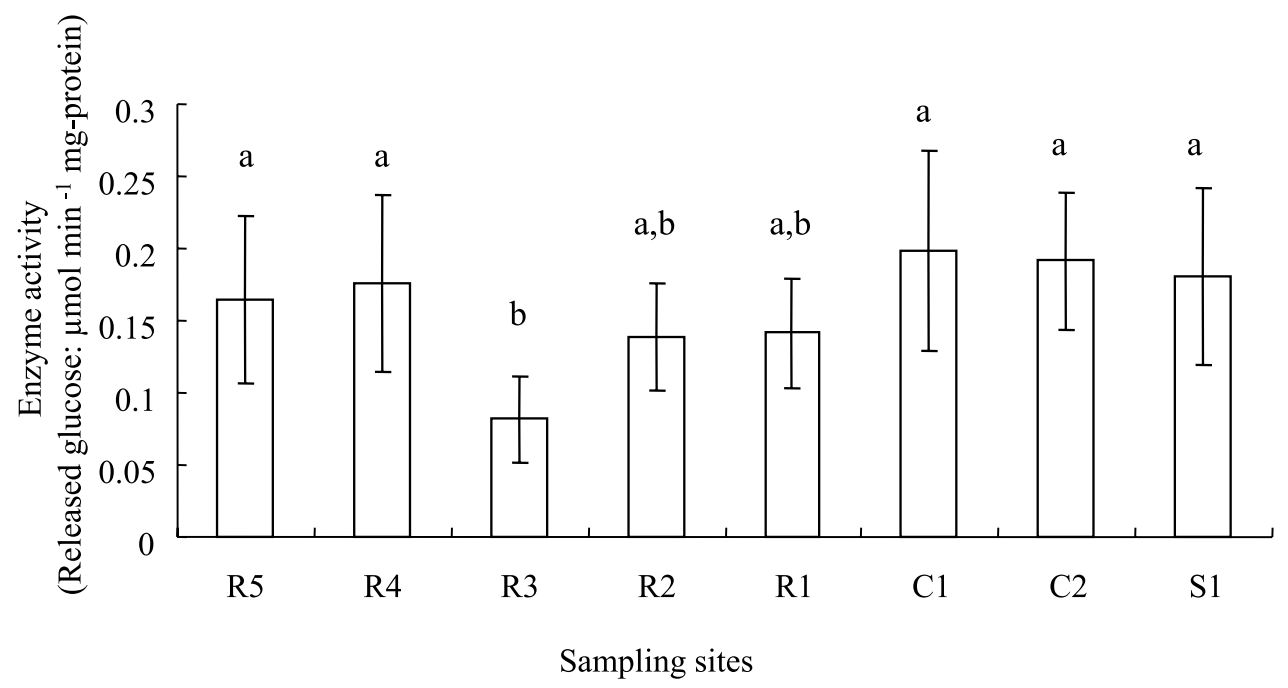

Fig. 4. Glucose releasing activity of digestive organ cellulases of blood cockles collected from different sites Different letters in the figure show how the level of activity differed significantly based on Turkey's HSD test $(P<0.05)$. C1, C2, R1, R2, R3, R4, R5 and S1 show the locations of the collection sites referred to in Fig. 1.

own, have been reported from termites ${ }^{25}$ and nematoda $a^{6,7}$. The occurrence of these cellulases of endogenous origin has also reported from aquatic invertebrates such as the abalone, sea urchin and brackish clam ${ }^{11,15,23}$.

In an agar plate assay and SDS-PAGE zymographic analysis, endo- $\beta-1,4$-glucanase activity was mainly detected, while all cellulase activities, including endo- $\beta$ 1,4-glucanase, cellobiohydrolase and $\beta$-glucosidase, were estimated in quantitative analysis to measure released glucose. As shown in Fig. 3, the blood cockle showed cellulase activity corresponding to endo- $\beta-1,4$-glucanase activity at 9.5 and $24.5 \mathrm{kDa}$ as intensive and smear broad bands respectively. In some blood cockles, other smear bands of higher molecular size were observed, as seen in Fig. 3. These smear bands were possibly because the cellulase responsible for the activity was glycoprotein. As shown in Fig. 4, the extract of the digestive organs of blood cockle could hydrolyze CMC to glucose, suggesting that the blood cockle has the ability to digest mangrove-derived cellulose to glucose owing to $\beta$-glucosidase. The activity level of blood cockle was almost equivalent to that of Corbicula japonica, but lower than those of $R u$ ditapes philippinarum and Anodonta woodiana ${ }^{10}$. It should be stressed that the blood cockle collected at R3, which is located from the river mouth to the coastal area, demonstrated slightly lower cellulase activity (Fig. 4). This might be due to the lower amount of mangrove-derived cellulose in the sediment ${ }^{12}$, but further study is required to determine the relation between the cellulase activity level and the amount of mangrove-derived cellulose in the sediment.
Recently, our studies showed hemi-cellulase, including mannanase, xylanase, xyloglucanase, and licheninase, all of which are required for the complete digestion of hard-degradable plant polysaccharides, are distributed among various aquatic invertebrates in addition to cellulase $\mathrm{e}^{10}$. There will be a need to study these hemi-cellulases in blood cockles to understand the digestive mechanisms of this species. It is also necessary to determine the identity of the gene, the enzyme of which the endo- $\beta-1,4-$ glucanase activity detected in the present study is ascribed, encoded on the chromosomes of blood cockles similar to other bivalves ${ }^{8-10}$. We are now trying to isolate cellulase genes from blood cockles to validate its endogenous origin in this species.

\section{Acknowledgements}

This study was supported by a Grant-in-Aid for Scientific Research from the Ministry of Education, Culture, Sports, Science and Technology of Japan (Nos. 21380131 and 22405030).

\section{References}

1. Bera-Maillet, C. et al. (2005) Xylanases and carboxymethylcellulases of the rumen protozoa Polyplastron multivesiculatum, Eudiplodinium maggii and Entodinium sp. FEMS Microbiol Let., 244, 149-156.

2. Bradford, M. M. (1976) A rapid and sensitive method for the quantitation of microgram quantities of protein utilizing the principle of protein-dye binding. Anal. Biochem., 72, 248-254. 
3. Chong, K. J. \& Peter, N. L. (1985) Determination of reducing sugars in the nanomole range with tetrazolium blue. $J$. Biochem. Biophys. Methods, 11, 109-115.

4. Chong, V. C. (2007) Mangroves-fisheries linkages-the Malaysian perspective. Bull. Mar. Sci., 80, 755-772.

5. Chow, C. M. et al. (1994) The cel3 gene of Agaricus-bisporus codes for a modular cellulase and is transcriptionally regulated by the carbon source. Appl. Environ. Microbiol., 60, 2779-2785.

6. Cosgrove, D. J. (2005) Growth of the plant cell wall. Nat. Rev. Mol. Cell Biol., 6, 850-861.

7. Kasai, A. \& Nakata, A. (2005) Utilization of terrestrial organic matter by the bivalve Corbicula japonica estimated from stable isotope analysis. Fish. Sci., 71, 151-158.

8. Kasai, A. et al. (2006) Food sources for the bivalve Corbicula japonica in the foremost fishing lakes estimated from stable isotope analysis. Fish. Sci., 72, 105-114.

9. Kikuchi, T. et al. (2005) Molecular and biochemical characterization of an endo- $\beta-1,3$-glucanase from the pinewood nematode Bursaphelenchus xylophilus acquired by horizontal gene transfer from bacteria. Biochem. J., 389, 117-125.

10. Niiyama, T. \& Toyohara, H. (2011) Widespread distribution of cellulase and hemi-cellulase activities among aquatic invertebrates. Fish. Sci., 77, 649-655.

11. Nishida, Y. et al. (2007) Isolation and primary structure of a cellulase from the Japanese sea urchin Strongylocentrotus nudus. Biochimie, 89, 1002-1011.

12. Okamura, K. et al. (2010) Spring tide hypoxia with relation to chemical properties of the sediments in the Matang Mangrove Estuary, Malaysia. JARQ, 44, 325-333.

13. Olson, D. et al. (2010) Deletion of the Cel48S cellulase from Clostridium thermocellum. Proc. Natl. Acad. Sci. USA., 107, 17727-17732.

14. Ronsness, P. A. (1968) Cellulolytic enzymes during morphogenesis in Dictyostelium discoideum. J. Bacterial., 96, 639-645.
15. Sakamoto, K. et al. (2007) Cellulose digestion by common Japanese freshwater clam Corbicula japonica. Fish. Sci., 73, 675-683.

16. Sakamoto, K. et al. (2008) Immunohistochemical, in situ hybridization and biochemical studies on endogenous cellulase of Corbicula japonica. Comp. Biochem. Physiol B., 150, 216-221.

17. Sakamoto, K. et al. (2009) Molecular cloning of endogenous $\beta$-glucosidase from common Japanese Brackish water clam Corbicula japonica. Gene, 435, 72-79.

18. Sakamoto, K. \& Toyohara, H. (2009) Molecular cloning of glycoside hydrolase family 45 cellulase genes from brackish water clam Corbicula japonica. Comp. Biochem. Physiol., B. 152, 390-396.

19. Sakamoto, K. \& Toyohara, H. (2009) Putative endogenous xylanase from brackish-water clam Corbicula japonica. Comp. Biochem. Physiol., B. 154, 85-92.

20. Sakamoto, K. \& Toyohara, H. (2009) A comparative study of cellulase and hemicellulase activities of brackish water clam Corbicula japonica with those of other marine Veneroida bivalves. J. Exp. Biol., 212, 2812-2818.

21. Smant, G. et al. (1998) Endogenous cellulases in animals: Isolation of $\beta-1,4$-endoglucanase genes from two species of plant-parasitic cyst nematodes. Proc. Natl. Acad. Sci. USA., 95, 4905-4911.

22. Chong, K. J. \& Peter, N. L. (1985) Determination of reducing sugars in the nanomole range with tetrazolium blue. $J$. Biochem. Biophys. Methods, 11, 109-115.

23. Suzuki, K. et al. (2003) Purification and cDNA cloning of a cellulase from abalone Haliotis discus hannai. Eur. J. Biochem., 270, 771-778.

24. Trinci, A. P. J. et al. (1994) Anaerobic fungi in herbivorous animals. Mycol. Res., 98, 129-152.

25. Watanabe, H. et al. (1998) A cellulase gene of termite origin. Nature, 394, 330-331.

26. Watanabe, H. \& Tokuda, G. (2010) Cellulolytic systems in insects. Annu. Rev. Entomol., 55, 609-632. 